\title{
Los tepetates y su dinámica sobre la degradación y el riesgo ambiental: el caso del Glacis de Buenavista, Morelos
}

\author{
Jorge Gama-Castro ${ }^{1, *}$, Elizabeth Solleiro-Rebolledo ${ }^{1}$, David Flores-Román ${ }^{1}$, \\ Sergey Sedov ${ }^{1}$, Héctor Cabadas-Báez ${ }^{2}$ y Jaime Díaz-Ortega ${ }^{2}$ \\ ${ }^{1}$ Instituto de Geología, Universidad Nacional Autónoma de México, \\ Ciudad Universitaria 04510, México, D.F. \\ ${ }^{2}$ Posgrado en Ciencias de la Tierra, Universidad Nacional Autónoma de México, \\ Ciudad Universitaria 04510, México, D.F. \\ *jgama@geologia.unam.mx
}

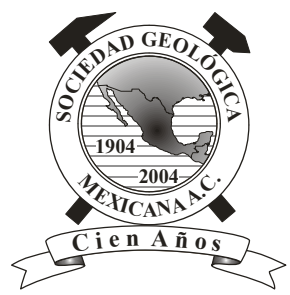

\section{Resumen}

El término tepetate se refiere a un horizonte endurecido, ya sea compactado o cementado, que se encuentra comúnmente en los paisajes volcánicos de México, subyaciendo a suelos o bien aflorando en superficie. Estos horizontes constituyen un elemento que participa activamente en la dinámica ambiental, ya que sus características físicas, mecánicas y químicas, tan restrictivas para el desarrollo de la vegetación (alta densidad, bajas conductividad hidráulica y retención de humedad así como pobre fertilidad). Su presencia, en consecuencia, representa un problema desde el punto de vista del manejo agrícola, ya que estas capas endurecidas, dificultan la labranza, siendo costosa su rehabilitación. Por otro lado, los tepetates debajo de suelos, producen discontinuidades litológicas, impiden la infiltración del agua y favorecen el escurrimiento lateral, marcando una superficie en donde se promueven los deslizamientos. Asimismo, el tepetate puede favorecer la erosión e impedir la recarga de acuíferos. Por esta razón, el objetivo del trabajo es presentar una visión sinóptica de los tepetates en México, mostrando la necesidad de renovar su investigación, considerando el alto grado de complejidad que presentan estos materiales para su estudio e interpretación. Particularmente se hace énfasis en los mecanismos de formación y se proporcionan datos concretos de los tepetates del Glacis de Buenavista, Morelos, que representa un estudio de caso, pero cuya ocurrencia no se constriñe a este sitio, sino que es un fenómeno que se repite en los paisajes volcánicos mexicanos, especialmente en los piedemontes. Su asociación con suelos arcillosos les confiere una firma espectral fácilmente reconocible en imágenes de satélite, por lo que su reconocimiento es relativamente fácil, de tal manera que representa una metodología sencilla que permite hacer evaluaciones más rápidas y confiables.

Palabras clave: tepetates, degradación, riesgo ambiental, remediación, Glacis de Buenavista.

Abstract

The name tepetate refers to indurated horizons, compacted or cemented, that are found in Mexican volcanic landscapes, underlaying soils or outcropping in the surface. These horizons represent an element that participates actively in the environmental dynamic, because of their characteristics (high density, low porosity, hydraulic conductivity, water holding capacity and poor fertility). These layers represent a problem in agriculture because its hardness difficults tillage and their remediation is expensive. Tepetates under soils produce lithological discontinuities that can generate landslides and erosion, because they block water infiltration, favoring lateral run off. Another environmental hazard is the limited aquifer recharge. In this paper a general overview of the tepetates and formation processes is presented, providing results from a study case in the Glacis de Buenavista, Morelos, but that are very common in the pediments of volcanic landscapes. In this area tepetates are related to clayey soils, both easily recognizable by their spectral signature in Landsat images, representing a methodology that can be used easily.

Key words: tepetates, degradation, environmental hazard, remediation, Glacis de Buenavista. 


\section{Introducción}

El término tepetate, en su acepción más elemental, ha sido inadecuadamente conceptualizado como "una capa muy dura que aflora o que eventualmente subyace a un suelo y que se caracteriza por su baja porosidad, limitada actividad biológica y bajo nivel de fertilidad, el cual demerita o impide su uso agrícola". La presencia de tepetates no representa únicamente un impedimento a la capacidad actual y potencial del suelo para producir de modo cualitativo y cuantitativo, bienes o servicios, también afecta, directa o indirectamente, al medio ambiente, reduciendo su aptitud para satisfacer las necesidades establecidas o implícitas (Flores-Román et al., 1990; Gama-Castro et al., 2006).

Los primeros trabajos sobre tepetates en México corresponden a las investigaciones de Shaw (1929) y Salazar (1938). Desde entonces, las dos líneas más representativas de dichos estudios son las referentes a su caracterización y cartografía (Valdés, 1970; Pacheco, 1979; Nimlos y OrtizSolorio, 1987; Dubroeucq et al., 1989; Rodríguez et al., 1999) así como la relativa a su rehabilitación e incorporación a la producción agrícola (García, 1961; Figueroa, 1975; Trueba, 1979; Quantin et al., 1993). Empero, recientemente, la investigación acerca de los tepetates ha sido extrapolada y vinculada a diversas disciplinas de las Ciencias de la Tierra, como son la paleopedología, estabilidad ambiental y cambio climático, entre otras (Geissert y Dubroeucq, 1990; Flores-Román et al., 1996; Escamilla-Sarabia et al., 2002; Solleiro-Rebolledo et al., 2003).

Es indudable que los aportes derivados de esas líneas de investigación, han contribuido significativamente al conocimiento básico y aplicado de los tepetates de México. Sin embargo, resulta sorprendente que con excepción de algunos pocos trabajos (Rey, 1979; Trueba, 1979; Ortíz-Solorio, 1986; Prat et al., 1997; Oropeza et al., 1997) no existe a nivel nacional, un acervo más amplio y confiable que relacione de modo cognoscitivo a los tepetates, con la dinámica de degradación del suelo y establezca su potencialidad como un riesgo ambiental.

Se sabe que la presencia de tepetates en México, concatenada a otra serie de limitantes, en las que destacan la erosión, el exceso de sales y la aridez, han determinado que de los $2000000 \mathrm{~km}^{2}$ que aproximadamente comprende la superficie del territorio nacional, sólo una cuarta parte puede ser utilizada para la agricultura y la ganadería y que menos de $0.04 \%$ pueda ser dedicada a plantaciones forestales. El resto de esta superficie está ocupada por desiertos y eriales $(2,151,106 \mathrm{ha})$ zonas urbanas $(463,479 \mathrm{ha})$ y cuerpos de agua (2,265189 ha) en su mayoría contaminados, así como áreas degradadas o perturbadas, en las que predominan los tepetates (2,2235,474 ha) (INEGI, 2003).

El análisis de las imágenes satelitales que cubren el territorio nacional, sugiere que este proceso de degradación del suelo, así como los riesgos ambientales que conlleva, avanzan con mayor rapidez que las medidas tomadas para su prevención y control.

Tratando de contribuir con la resolución de dicha problemática, el objetivo principal de este trabajo consiste en proporcionar una visión global sobre los tepetates en México y su incidencia sobre la calidad de vida, es decir, sobre la calidad de los alimentos, del agua y del aire.

\section{Definición y distribución de los tepetates}

Tepetate es un término que tiene un amplio rango semántico en el uso popular y técnico. Deriva del náhuatl tepétlatl, vocablo compuesto por las raíces tetl que significa piedra y pétlatl, petate (Figura 1). Literalmente se le ha traducido como "petate de piedra"; "parecido a piedra" o "roca suave". Para los aztecas, este término estaba contenido en su clasificación de materiales y representaba el taxón de un tipo de suelo agrícola difícil de labrar (Gibson, 1996). En contraste, al arribo de los españoles, el término tepetate fue sinónimo de suelo no agrícola, por su baja calidad (OrtizSolorio, 1999).

Desde épocas Precolombinas, esta capa endurecida, en ocasiones cementada, ha representado para México y la mayoría de los países del arco volcánico centro y suramericano, un problema que incide sobre la calidad y productividad del suelo y de su contexto ambiental (Williams y Ortíz-Solorio, 1981; Cervantes et al., 2005; Gama-Castro et al., 2005). En consecuencia, también ha sido descrita en la mayoría de los países de América con nombres locales; por ejemplo: en Centroamérica, se le llama talpetate; en Colombia hardpán, duripán y cangagua en la parte sur del país, este último término se utiliza también en Ecuador; en Perú se le denomina hardpán y en Chile cangagua, moromoro, tosca y ñadis (Zebrowski, 1992).

Por otra parte, en Estados Unidos a las capas compactadas o cementadas, exclusivamente por procesos pedológicos, se les considera como materiales para-líticos (análogos a roca) y en ellos se incluyen a los fragipanes (capa compactada) y a los duripanes (capa cementada por $\mathrm{SiO}_{2}$ ). Los primeros, en contacto prolongado con el agua colapsan su estructura, en tanto que los segundos, bajo condiciones similares, mantienen su estabilidad estructural

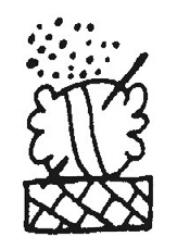

Tepetate Areno-arcilloso

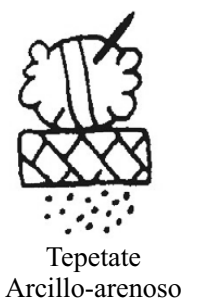

Figura 1. Glifos alusivos a diferentes tipos de tepetates (Códice Vergara, siglo XVI). En la cosmovisión náhuatl, el término tepetate involucra en su contexto, un profundo conocimiento etnopedológico que integra a 15 diferentes materiales, asociados con limitantes y riesgos para el suelo y su ecosistema (Williams 1980). 
por tiempo indefinido (SSS-USDA, 1998). El término pan, se aplica a capas compactadas, endurecidas (hardpan) o que presentan contenidos altos de arcilla (claypan), por lo que son relativamente impermeables al agua, al aire y al crecimiento radicular. Dichas capas, pueden tener un origen pedogenético (edáfico) o bien ser formadas por procesos geológicos en el momento de su emplazamiento o por cambios diagenéticos.

En el caso particular de México, Flores-Román et al. (1990) estimaron que aproximadamente el 30\% del territorio nacional estaba afectado en mayor o menor grado por la presencia de tepetates (Figura 2). Esta estimación incluía en su contexto, a todas aquellas capas que presentaban diferentes grados de endurecimiento. Entre ellas, capas compactadas, pero no cementadas (fragipanes); capas cementadas por $\mathrm{SiO}_{2}$ (duripanes); por $\mathrm{CaCO}_{3}$ (petrocálcico); por $\mathrm{CaSO}_{4}$ (petrogípsico); por $\mathrm{Fe}_{2} \mathrm{O}_{3}$ (petroplintitas) y por diversas sales (petrosálico).

Posteriormente, Zebrowski (1992) estimó con base en la cartografía de INEGI, que los tepetates, particularmente los duripanes, cubrían un área de $30700 \mathrm{~km}^{2}$. En ese mismo año, Guerrero et al., (1992) estimaron una cobertura de 140 $000 \mathrm{~km}^{2}$, incluyendo no sólo duripanes, sino a horizontes petrocálcicos y petrogípsicos. En general, el problema común en estas estimaciones es la escala y la intensidad de muestreo, las cuales resultan inapropiadas para establecer medidas preventivas y correctivas, dentro de un ordenamiento territorial.

De acuerdo con los principios establecidos por Oldeman (1988) resulta indudable que esta heterogeneidad, discordante tanto en métodos como en estimaciones, no solo impide evaluar con exactitud el riesgo que representan los tepetates en el ecosistema, sino que además, limita severamente el tomar medidas correctivas para su rehabilitación y manejo. En la actualidad un inventario confiable acerca de la superficie ocupada por los tepetates, pudiera ser viable con herramientas como la teledetección, los sistemas de información geográfica y el análisis automatizado de imágenes, combinado con trabajo de campo. Un ejemplo de ello se ilustra en la Figura 3 que muestra la distribución y variabilidad espacial de los tepetates localizados en el cerro San Lucas, Valle de Teotihuacan, Estado de México. En esta imagen de satélite se observan las firmas espectrales las cuales fueron automáticamente analizadas, mediante el uso del software Image-Pro Plus versión 4.1. Mediante dicho análisis se obtuvieron patrones característicos que posteriormente fueron validados en campo.

Se estima que la distribución de los tepetates, está condicionada por los factores topografía, material parental y clima, este último, principalmente de tipo semiárido, aunque también suelen presentarse en climas más húmedos, como es el caso del estado de Veracruz, donde tienden a formar suelos, una vez que el tepetate se intemperiza (FloresRomán et al., 1992; Peña y Zebrowski, 1992; GutiérrezCastorena y Ortíz-Solorio, 1992). En general, se localizan en altitudes comprendidas entre 1800 y 2800 m.s.n.m. De modo prioritario, se presentan en geoformas erosionales (piedemontes) constituidas principalmente por materiales de origen volcánico (piroclásticos) de edad cuaternaria. Estas geoformas, topográficamente están caracterizadas por pendientes superiores a 5-10\%, que muestran una longitud y orientación variables.

Dependiendo de la posición que ocupen los tepetates en el perfil de la pendiente, pueden estar subyaciendo a un

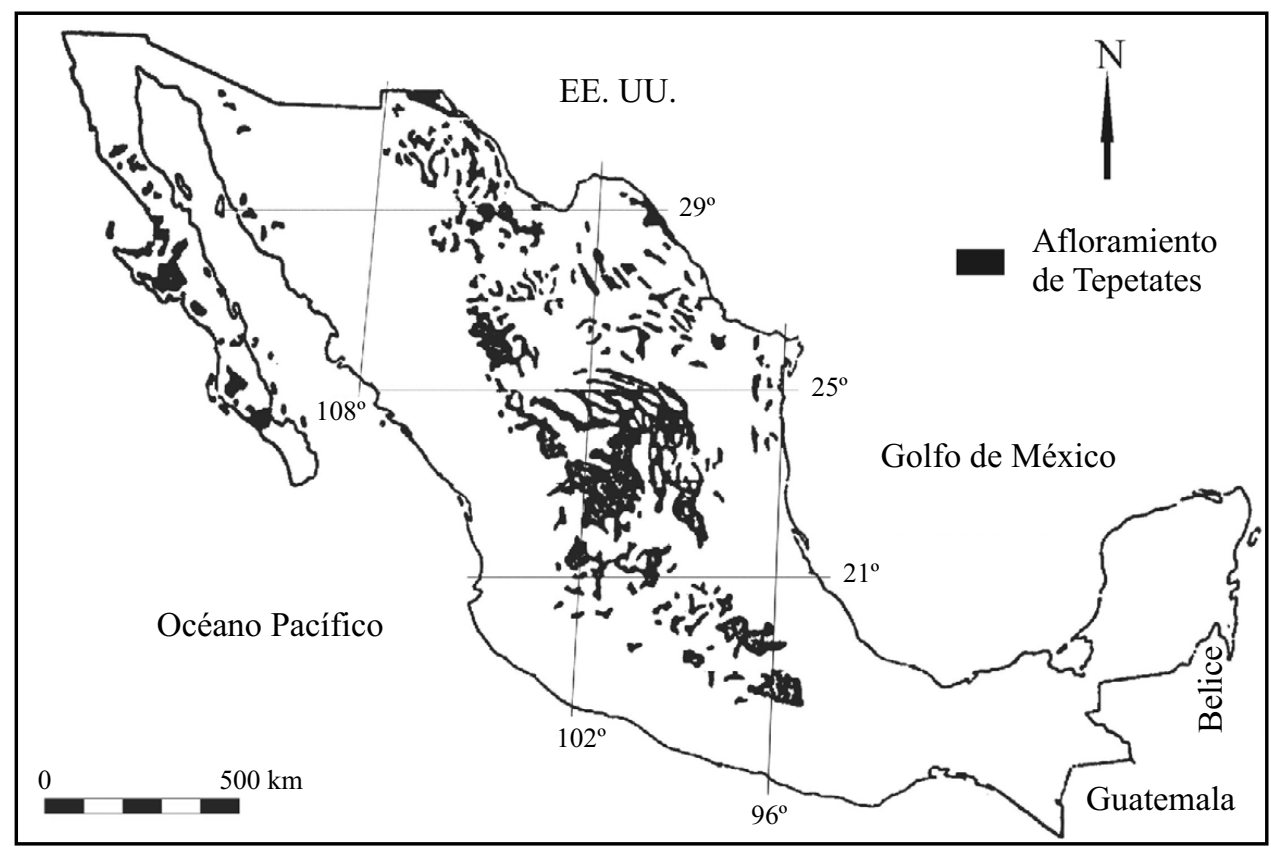

Figura 2. Distribución espacial de los tepetates en el Territorio Nacional, según Flores-Román et al. (1992). 


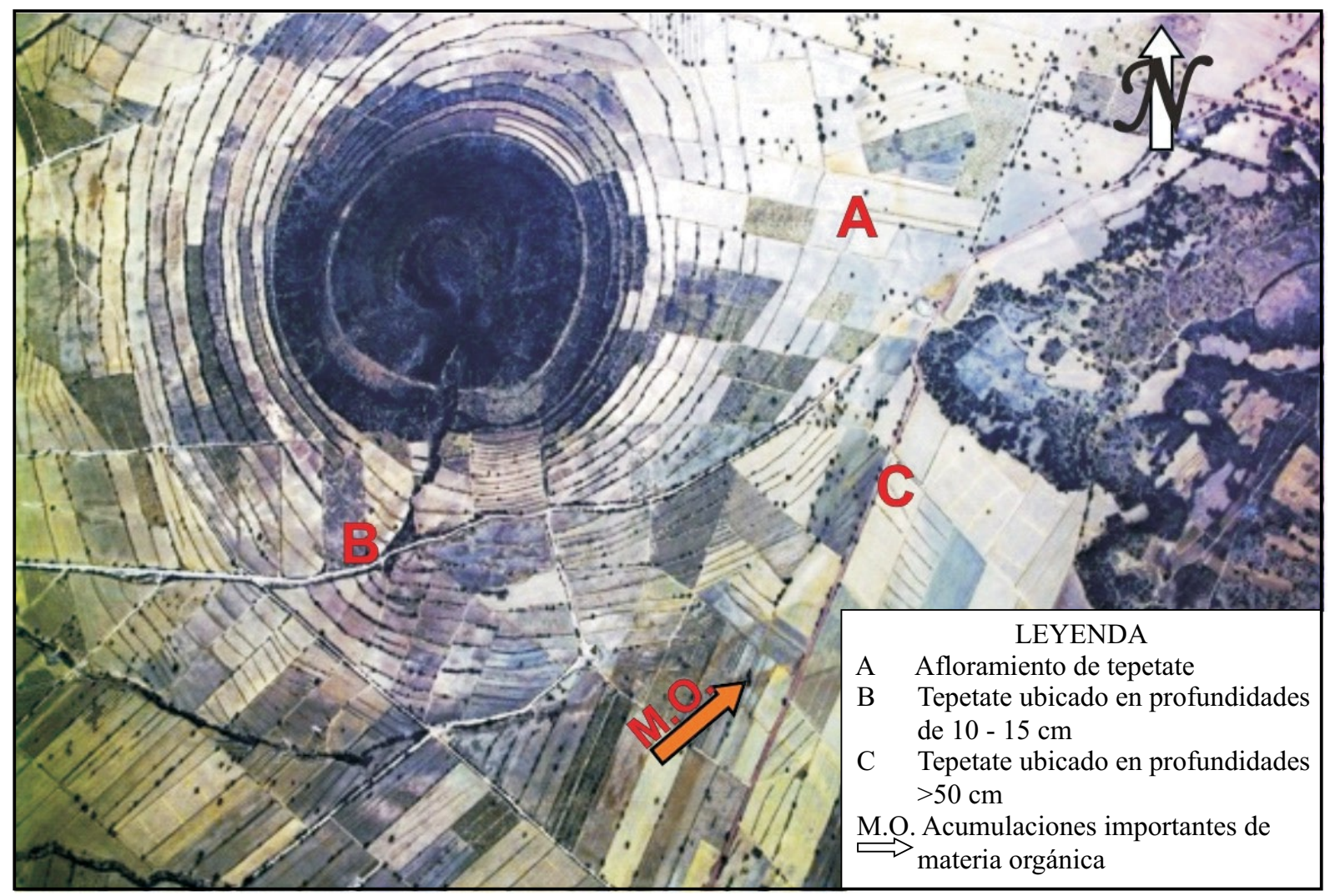

Figura 3. Distribución y variabilidad espacial de los tepetates localizados en el cerro San Lucas, Valle de Teotihuacan, Estado de Mexico. En esta figura se observan diferentes firmas espectrales, caracterizando cada una, la distribución espacial de los tepetates y su profundidad relativa en el suelo. Imagen cortesía de Julia Pérez-Pérez.

suelo bien desarrollado, por ejemplo en la cima, o bien, estar sepultados por una delgada capa de pedisedimento, mezclado con aluvión y coluvión, en el pie de pendiente o aflorando en la espalda de la pendiente (Figura 4).

Aunque existen muchas discrepancias al respecto, de acuerdo con Zebrowski (1992) los tepetates se forman, de modo preferencial, en climas subhúmedos (precipitación anual $<800 \mathrm{~mm}$ ) caracterizados por una estación seca que dura de cuatro a seis meses (Dubroeucq et al., 1989; Servenay et al., 1996) donde la tasa de evapotranspiración generalmente es mayor que la precipitación. Se sabe que los tepetates no afloran en las zonas de riego y tampoco en los bosques bien conservados, bien por que no existen bajo el suelo o por que este último está protegido de la erosión, no se ha eliminado y, en consecuencia, la capa endurecida permanece en el subsuelo.

\section{Caracterización de los tepetates}

En 1996, durante el III Simposio Internacional de Suelos Volcánicos Endurecidos, celebrado en Quito, Ecuador, se propuso caracterizar a los tepetates como un horizonte endurecido, de origen volcánico, cuyo material parental está básicamente constituido por materiales piroclásticos bajo forma de caídas, o flujos, o bien como suelos volcánicos degradados.

Con base en las investigaciones realizadas por diferentes autores (v.g. Etchevers et al., 1992; Gutiérrez-Castorena y Ortíz-Solorio, 1992; Miehlich, 1992; Peña y Zebrowski, 1992; Peña et al., 1992) resulta posible inferir que independientemente de su origen, los tepetates siempre presentan, dentro de un rango de oscilación, propiedades físicas, mecánicas y químicas que le son comunes entre sí. Destaca su compactación o cementación, que se reflejan en densidades aparentes altas $\left(1.7-1.9 \mathrm{~g} / \mathrm{cm}^{3}\right)$, una porosidad baja de 13 a 24\% (Figura 5), así como conductividades hidráulicas y retención de humedad bajas. Estas características, impiden o limitan significativamente la incorporación, rápida de plantas primarias, debido a que limitan su crecimiento radicular lo que propicia una baja cobertura vegetal y la posterior erosión del suelo. Como se observa en la Tabla 1, la susceptibilidad de estos materiales a la erosión (Factor $\mathrm{K})$ en todos los casos es alta y concuerda con lo encontrado por Prat et al. (1997).

De acuerdo con los trabajos realizados sobre las propiedades físicas, los tepetates exhiben una matriz compuesta por arena, limo y menores porcentajes de arcilla (Miehlich, 1992; Peña y Zebrowski, 1992), sin embargo en ocasiones pueden presentar contenidos altos de esta fracción (Tabla 


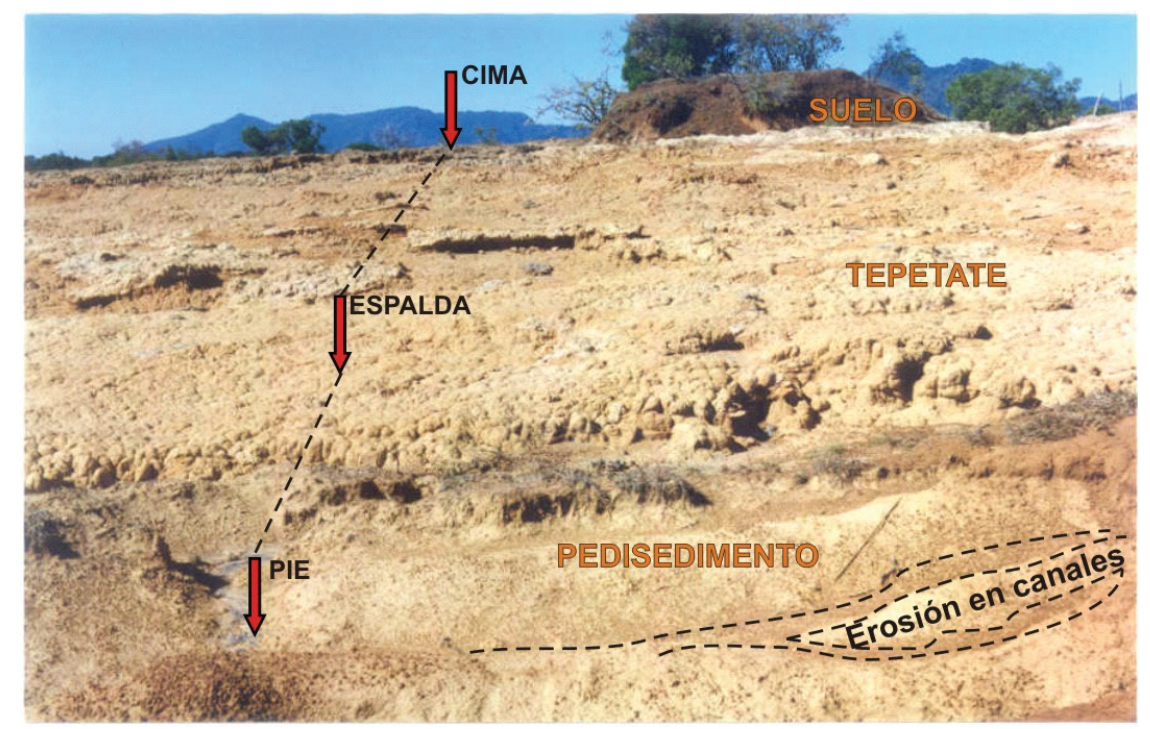

Figura 4. Distribución de los tepetates en función del perfil de pendiente. En esta figura se observa un paisaje típico del Glacis de Buenavista, Morelos. En ella, se ilustra la dinámica de la pendiente. En los sitios más estables desde el punto de vista geomorfológico, es posible encontrar suelos relictos (paleosuelos) en tanto que en los sitios menos estables (espalda) sólo se encuentra el tepetate aflorando. La parte correspondiente al pie de la pendiente se caracteriza por sus procesos acumulativos-erosivos.

1). Esta variabilidad constituye una problemática para los trabajos encaminados a la rehabilitación de los tepetates, ya que cada clase textural genera un comportamiento físico y mecánico independiente, el cual, indudablemente, requiere de una investigación específica.

Un ejemplo de la variabilidad en el comportamiento mecánico de los tepetates ha sido evaluado con relación a su resistencia a la compresión simple. De acuerdo con los resultados de Flores-Román et al., (1996), generalmente los fragipanes tienen una resistencia menor a $10 \mathrm{~kg} / \mathrm{cm}^{2}$ y los duripanes mayor que $25 \mathrm{~kg} / \mathrm{cm}^{2}$ siendo estos últimos los que sufren mayor deformación. Nimlos y Hillery (1990) también muestran este comportamiento variable en los diferentes tipos de tepetates analizados, cuya resistencia, además, disminuye cuando se incrementa el contenido de humedad.

Los análisis efectuados en cuanto a sus propiedades hidráulicas revelan que los valores más bajos de infiltración se tienen en los duripanes, variando de $10 \mathrm{~cm} / \mathrm{h}$ en el suelo superficial hasta $2 \mathrm{~cm} / \mathrm{h}$ cuando se llega al tepetate (Flores-Román et al., 1992). Los resultados encontrados por Nimlos y Hillery (1990) coinciden con una baja conductividad hidráulica, que va de $5.4 \times 10^{-4}$ hasta $130 \times 10^{-4}$ $\mathrm{cm} / \mathrm{h}$ siendo los materiales con carbonatos los que exhiben los valores más altos.

Aunado a estas características físicas, se debe señalar que los tepetates también poseen propiedades químicas que les confiere una baja fertilidad natural, aún cuando algunos de ellos pueden tener una composición mineralógica, potencialmente rica en cationes intercambiables, los porcentajes de materia orgánica y nitrógeno total son pequeños (Flores-Román et al., 1996), la primera que se requiere para la retención de nutrimentos y el segundo que representa un elemento esencial para el desarrollo vegetal (Tabla 2). Estas deficiencias en materia orgánica se deben a que la baja porosidad que los tepetates tienen, de manera que la vegetación difícilmente puede colonizarlos. Sin embargo, también es posible que después de su emplazamiento no haya habido tiempo suficiente para que pudieran ser afectados por la biota.

\section{Origen de los tepetates}

El conocimiento actual sobre la génesis de los tepetates, de modo similar al conocimiento relativo a la extensión que ocupan en el territorio nacional y su tasa de avance como factor de degradación, muestra un grado significativo de incertidumbre. Así, de acuerdo con los diferentes estudios realizados sobre sus propiedades diagnósticas, es posible inferir que éstos presentan tres probables orígenes:

\subsection{De origen geológico}

Los primeros estudios realizados en México acerca del origen de los tepetates, reportaron que éstos se podían constituir a partir de diferentes materiales piroclásticos que mostraban distintos grados de intemperismo físico y químico, e inclusive lahares. Por ejemplo, Salazar (1938), Llerena (1947) y García (1961) consideraron a los tepetates del valle de México como tobas "pumosas" del Terciario o Cenozoico en proceso de intemperismo. Valdés (1970) mencionó que los tepetates de la cuenca de México se formaron por el arrastre aluvial de un fanglomerado que posteriormente se consolidó, y Heine y Schönhals (1973) 

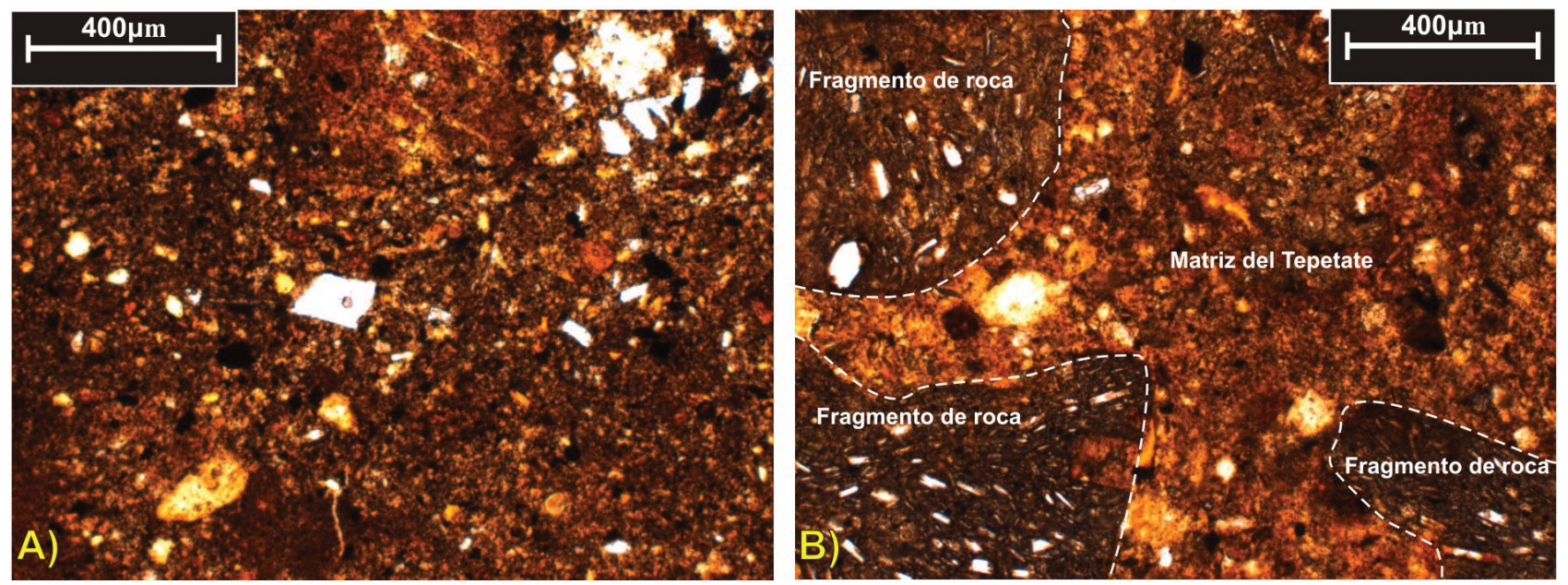

Figura 5. Microfotografías del grado de compactación y cementación en un tepetate. a) Detalle de la matriz de un tepetate, compuesta principalmente por fracciones de limo, arcilla y en pequeñas proporciones arena, con una baja porosidad. b) Matriz de un tepetate, compuesta por materiales finos de limo y arcilla, que mantiene cementados a fragmentos de rocas volcánicas. Fotografías tomadas con microscopio petrográfico, luz natural.

citaron que el origen de los mismos era por depósitos de loess posteriores a grandes glaciaciones. Sin embargo, de acuerdo con Rodríguez et al. (1999) los resultados expuestos por dichos autores, no fueron suficientemente precisos y dejaron ambigüedades sobre la génesis de las capas endurecidas, concluyendo que los tepetates pueden tener orígenes diversos.

Zebrowski (1992) reconoce dos procesos geológicos para explicar el endurecimiento de los horizontes:

A. Consolidación-compactación simple o por la hidroconsolidación de materiales volcánicos transportados por el agua. En ambos casos, siempre existe un incremento en la densidad aparente del material, una mayor dureza y consecuentemente, una disminución de la porosidad.
B. Endurecimiento de los materiales volcánicos en el momento de su depósito y posterior enfriamiento, este es el caso de los flujos piroclásticos.

\subsection{De origen diagenético-pedológico}

Varios autores como: Nimlos (1990); Flores-Román et al. (1992); Miehlich (1992); Quantin (1992) y Bertaux y Quantin (1994) entre otros, afirmaron que los tepetates se originan a partir de antiguos depósitos de cenizas volcánicas depositadas in situ o retrabajadas, que sufrieron tanto procesos diagenéticos (hidroconsolidación), como pedogenéticos (v.g. argilización; silificación) que contribuyeron a

Tabla 1. Características físicas diagnósticas en los tepetates.

\begin{tabular}{|c|c|c|c|c|c|c|c|c|}
\hline $\begin{array}{c}\text { Tipo de Tepetate } \\
\text { SSS-USDA } \\
1998\end{array}$ & $\begin{array}{c}\text { Densidad } \\
\text { Aparente } \\
\left(\mathrm{gr} / \mathrm{cm}^{3}\right)\end{array}$ & $\begin{array}{c}\text { Porosidad } \\
(\%)\end{array}$ & $\begin{array}{c}\text { Conductividad } \\
\text { Hidráulica } \\
(\mu \mathrm{m} / \mathrm{s})\end{array}$ & $\begin{array}{c}\text { Retención de } \\
\text { Humedad } \\
(\%)\end{array}$ & $\begin{array}{c}\text { Erodabilidad } \\
\text { (Factor K) }\end{array}$ & Arena & $\begin{array}{l}\text { Clase Textural } \\
\text { Porcentajes de } \\
\text { Limo }\end{array}$ & Arcilla \\
\hline & 1.70 & 21.0 & 4.5 & 5.0 & 0.28 & 80.13 & 9.23 & 10.64 \\
\hline Fragipán ${ }^{* 1}$ & Alta & Baja & Moderada & Muy baja & Moderada & & Arena migajosa & \\
\hline & 1.90 & 15.0 & 0.1 & 11.0 & 0.37 & 39.00 & 45.50 & 15.50 \\
\hline Fragipán ${ }^{* 1}$ & Alta & Baja & Baja & Baja & Alta & & Migajón franco & \\
\hline & 1.96 & 13.0 & 0.07 & 12.0 & 0.33 & 30.19 & 39.40 & 30.41 \\
\hline Fragipán ${ }^{* 1}$ & Alta & Baja & Baja & Baja & Moderada & & Migajón arcilloso & \\
\hline & 1.80 & 19.0 & $<0.01$ & 9.0 & 0.45 & 9.00 & 65.00 & 26.00 \\
\hline Duripán *2 & Alta & Baja & Muy baja & Muy baja & Alta & & Migajón limoso & \\
\hline & 1.92 & 20.0 & 0.04 & 10.5 & 0.33 & 23.00 & 42.00 & 35.00 \\
\hline Duripán *2 & Alta & Baja & Baja & Baja & Moderada & & Migajón arcilloso & \\
\hline & 1.90 & 24.0 & $<0.01$ & 10.2 & 0.40 & 22.00 & 60.00 & 18.00 \\
\hline Duripán *2 & Alta & Baja & Muy baja & Baja & Alta & & Migajón limoso & \\
\hline
\end{tabular}

${ }^{* 1}$ Flores-Román et al., 1992, ${ }^{* 2}$ Flores-Román et al., 1996. 
Tabla 2. Características químicas diagnósticas en los tepetates

\begin{tabular}{|c|c|c|c|c|c|c|c|c|}
\hline $\begin{array}{l}\text { Tipo de tepetate } \\
\text { SSS-USDA, } 1998\end{array}$ & $\begin{array}{c}\text { Materia } \\
\text { orgánica } \\
(\%)\end{array}$ & $\begin{array}{c}\text { Nitrógeno } \\
\text { total } \\
(\%)\end{array}$ & $\mathrm{Ca}^{++}$ & $\begin{array}{r}\text { Bases in } \\
(\mathrm{meq} \\
\mathrm{Mg}^{++}\end{array}$ & $\begin{array}{l}\text { nbiables } \\
\mathrm{Na}^{+}\end{array}$ & $\mathrm{K}^{+}$ & $\begin{array}{c}\text { Saturación de } \\
\text { bases } \\
(\%)\end{array}$ & $\begin{array}{l}\mathbf{p H} \\
\mathrm{H}_{2} \mathrm{O} \\
1: 2.5\end{array}$ \\
\hline \multirow{3}{*}{ Fragipán * 1} & 0.10 & 0.03 & & & & & 100.0 & \\
\hline & Muy pobre & Pobre & 19.0 & 11.0 & 0.9 & 0.3 & Alta & 6.40 \\
\hline & 0.10 & 0.01 & & & & & 65.0 & \\
\hline Fragipán $* 1$ & Muy pobre & Pobre & 11.0 & 10.0 & 0.3 & 0.7 & Media & 6.90 \\
\hline \multirow[t]{2}{*}{ Fragipán $* 1$} & $\begin{array}{c}0.80 \\
\text { Muy pobre }\end{array}$ & $\begin{array}{c}0.03 \\
\text { Pobre }\end{array}$ & 10.0 & 8.0 & 1.1 & 0.2 & $\begin{array}{c}100.0 \\
\text { Alta }\end{array}$ & 7.10 \\
\hline & 0.06 & 0.01 & & & & & 87.0 & \\
\hline Duripán $* 2$ & Muy pobre & Pobre & 17.2 & 12.7 & 2.6 & 1.2 & Alta & 6.40 \\
\hline & 0.05 & 0.01 & & & & & 87.0 & \\
\hline Duripán $* 2$ & Muy pobre & Pobre & 8.6 & 7.7 & 2.3 & 0.6 & Alta & 6.20 \\
\hline & 0.02 & 0.01 & & & & & $\begin{array}{c}65.0 \\
\text { Media }\end{array}$ & \\
\hline Duripán $* 2$ & Muy pobre & Pobre & 5.1 & 2.1 & 0.7 & 0.2 & Media & 5.60 \\
\hline
\end{tabular}

${ }^{* 1}$ Flores-Román et al., 1992, "2 Flores-Román et al., 1996.

su compactación y/o cementación. En estas investigaciones, también se coincidió al considerar que los productos secundarios generados por el intemperismo de la ceniza son principalmente amorfos $\left(\mathrm{SiO}_{2} ; \mathrm{Al}_{2} \mathrm{O}_{3}\right)$ y en menor grado arcillas. Al respecto, Hidalgo et al. (1992) consideraron que una parte de esta sílice, forma ópalo-A orgánico e inorgánico, el cual se incorpora a los minerales de arcilla. Los cambios en el régimen de humedad del suelo, debido a su degradación, propician un incremento en su compactación y endurecimiento de las arcillas ricas en ópalo-A, las cuales forman el tepetate.

De hecho, se ha determinado que el endurecimiento secundario ocurre bajo condiciones templadas o semiáridas (Geissert, 1992), lo que permite la liberación de compuestos que al lixiviarse y depositarse, actúen como cementantes (v.g. sílice libre, carbonato de calcio). Éstos, son particularmente eficientes si en la matriz del horizonte en que se depositan, son absorbidos por la arcilla.

4.3. Formados como un producto de la degradación física del suelo

Según la FAO-PNUMA (1980) los factores que propician la degradación física del suelo y la posterior formación de tepetates, se dividen en:

1. Naturales. Están constituidos por el factor climático $\mathrm{y}$ el factor edáfico. El primer factor, se refiere a escasez de lluvias y/o a la torrencialidad de las mismas. El factor edáfico comprende a la alteración no antropogénica de las características diagnósticas del suelo (consolidación, compactación, cementación). Ambos factores, pueden propiciar alteraciones notables en la cubierta vegetal y en la dinámica de la biota del suelo.

2. Antrópicos. En este concepto se incluyen aquellos síntomas que resultan de las actividades antrópogénicas y/o tecnogénicas. Los causales más comunes son: (i) deforestación por efecto de la tala inmoderada, (ii) sobreexplotación de la vegetación, lo que propicia un decremento en el porcentaje de la cubierta vegetal, (iii) sobrepastoreo, el cual genera compactación del suelo por carga confinada, y (IV) actividades industriales y urbanizadoras.

De acuerdo con la FAO-PNUMA (1980) este tipo de degradación se caracteriza por propiciar en el suelo la acción de diversos procesos, destacando los siguientes: (i) deterioro severo de la estructura del horizonte superficial del suelo (horizonte A) lo cual lo hace muy susceptible a la erosión; (ii) pérdida del horizonte $\mathrm{A}$, debido a la erosión; (iii) afloramiento del horizonte subyacente y exposición a variaciones en su contenido de humedad por humedecimiento y secado reiterados, lo cual ocasiona su consolidación y compactación (hidroconsolidación) y (iv) disminución de su porosidad, e incremento de su densidad y dureza, debido a la compactación. En estas condiciones, la matriz del horizonte compactado, puede posteriormente ser cementada por la precipitación de diferentes lixiviados, principalmente sílice libre $\left(\mathrm{SiO}_{2}\right)$. En este aspecto se debe señalar que, en realidad, son pocos los trabajos en los que se documenta claramente la presencia de este tipo de sílice, con excepción de los efectuados por Poetsch (2004). De hecho, Hidalgo et al. (1992) concluyen que la cantidad de sílice libre es muy pequeña, por lo tanto no explica por si sola la cementación de los tepetates de la Sierra Nevada.

\section{Los tepetates como un factor de degradación del suelo y de riesgo ambiental. El Glacis de Buenavista, Morelos: un caso de estudio}

Un ejemplo que ilustra el riego ambiental propiciado por la presencia de los tepetates, se localiza en el espacio geográfico ocupado por el Glacis de Buenavista (GBV). Esta 


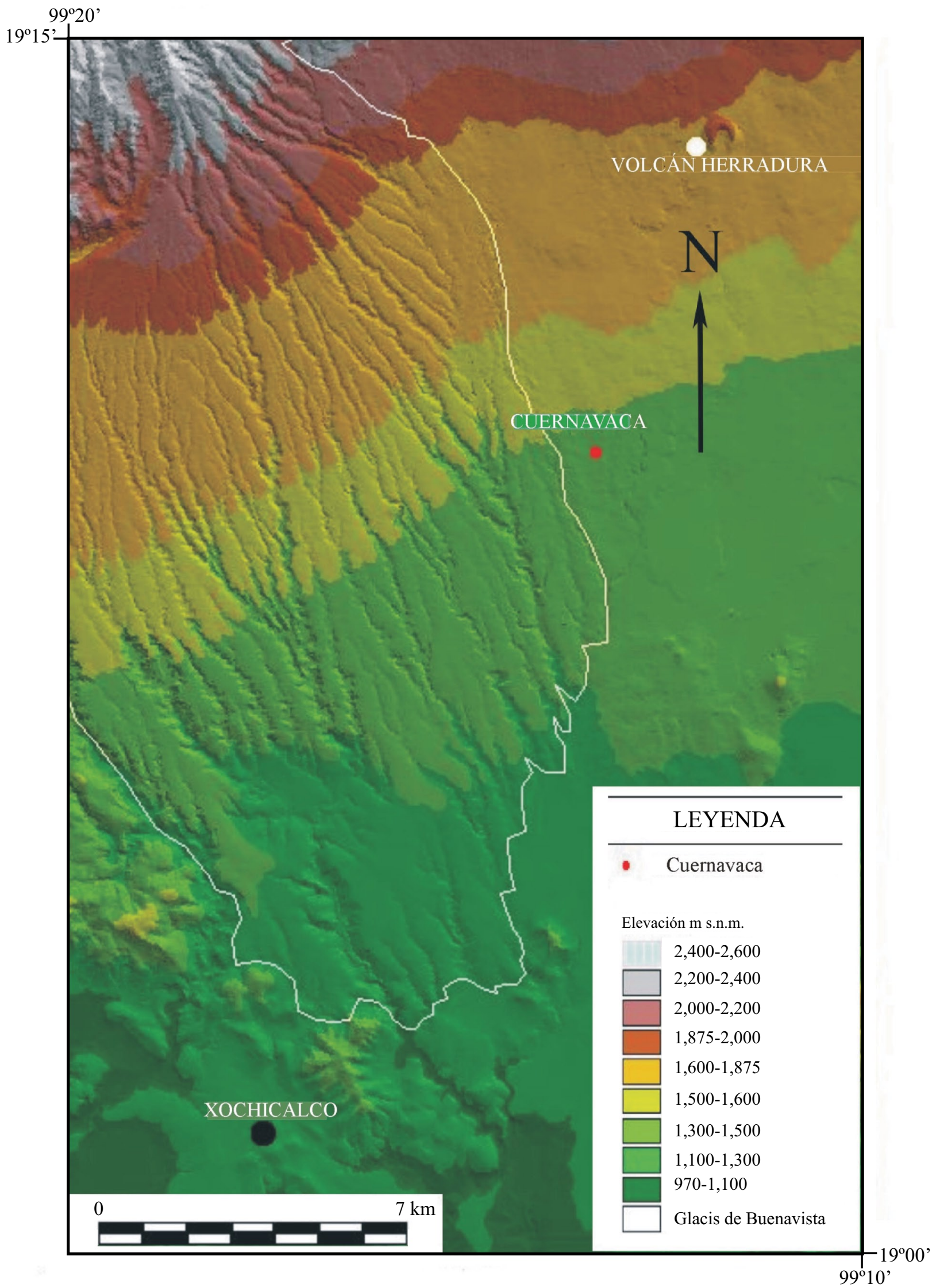

Figura 6. Localización y distribución altitudinal del Glacís de Buenavista (GBV), Morelos. 


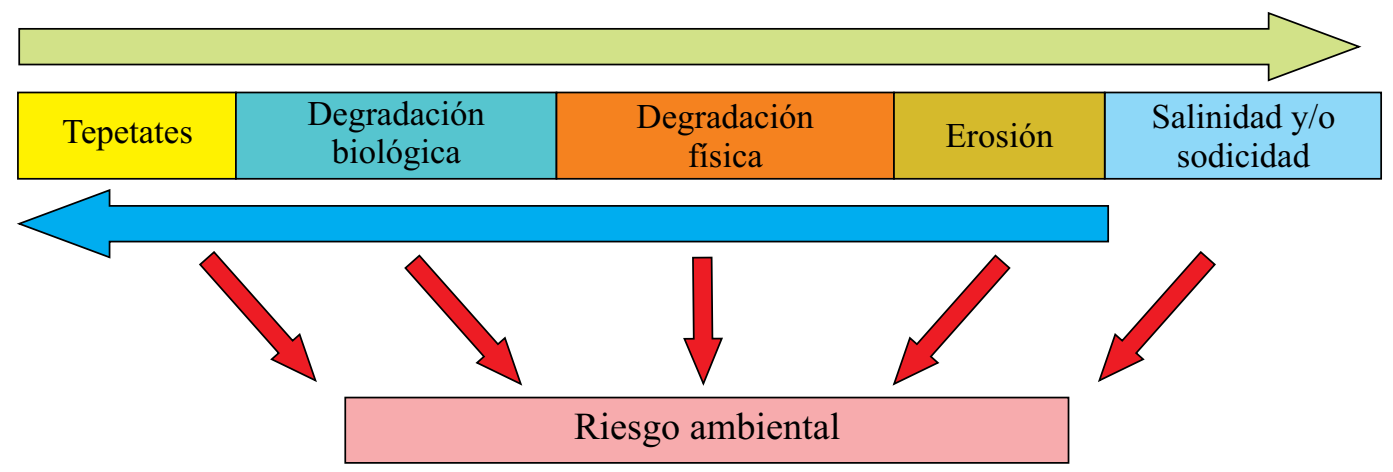

Figura 7. Interacción de la dinámica de los tepetates con la degradación del suelo y su riesgo ambiental.

unidad terrestre se extiende entre los estados de Morelos y México, constituyendo un piedemonte que ocupa una superficie aproximada de 20,272 ha la cual está comprendida entre $\operatorname{los} 1,100$ a los 2,800 $\mathrm{m}$ de altitud (Escamilla-sarabia et al., 2002). Desde el punto de vista geomorfológico, el GBV constituye un abanico volcaniclástico, caracterizado por una red de drenaje paralelo-asimétrica (Figura 6). La fuente principal de sedimentos es el volcán Zempoala, ubicado al norte de esta geoforma. Su origen está asociado a cambios de regímenes climáticos, procesos de gelifracción y de ladera (Martínez y López, 2005). La investigación realizada por Ortiz (1977) sitúa al GBV en el Holoceno, en tanto que Palacio- Prieto (1982) le atribuye una edad pliocénica.

Los tipos climáticos que caracterizan al GBV de norte a sur, son tres: templado subhúmedo, semicálido subhúmedo y el cálido subhúmedo. Estos tipos climáticos junto con los gradientes altitudinales, determinan la distribución espacial de la vegetación. En las partes más altas de GBV, caracterizadas por la presencia de un clima templado, predomina el bosque de coníferas. A medida que decrece la altitud y se incrementa la temperatura, dicho bosque va siendo sustituido por el bosque mixto, bosque de juníperos, selva baja y finalmente, bosque de galería. En general el área presenta diferentes tipos de procesos de degradación de suelos y deterioro ambiental, la erosión hídrica es predominante (Figura 4).

Con excepción de algunos suelos relictos (paleosuelos) formados durante el Pleistoceno Tardío-Holoceno, la mayoría de los suelos modernos se caracterizan por su escaso espesor y desarrollo débil, siendo su principal limitante de calidad, la presencia de un tepetate en su perfil, el cual con mucha frecuencia aflora (Figura 4). Los estudios realizados por Solleiro-Rebolledo et al. (2003) permiten establecer que los tepetates que caracterizan esta área, se formaron a partir de flujos hiperconcentrados de materiales piroclásticos, fechados en 12,190 años A.P. Además, se evaluó con base en FAO-PNUMA (1980) y FAO-UNESCO (1984) que la presencia de tepetates, deteriora, en diferentes grados, la aptitud natural del suelo para funcionar dentro de los límites de este ecosistema, lo que genera riesgos a los demás elementos de su contexto ambiental.
Los principales procesos de degradación del suelo y riesgos colaterales observados, en esta geoforma, se sintetizan en la Figura 7. De hecho, la presencia de los tepetates en superficie es indicativa de la degradación de suelos y un riesgo para su ecosistema. A su vez, los diferentes tipos secundarios de degradación que genera dicho proceso, potencialmente coadyuvan a la formación o exposición de nuevos.

Como se ha mencionado, la mayoría de los tepetates presentes en el GBV se presentan aflorando o se localizan a unos cuantos centímetros bajo la superficie del suelo. En todos los casos, representan una severa limitante al crecimiento radicular de la vegetación, la infiltración del agua y el paso del aire. De acuerdo con FAO (1991) éstas características propician un escaso desarrollo de vegetación y por consiguiente, de la biomasa, lo que genera una producción pobre de materia orgánica por área/tiempo (Tabla 2). Dicha deficiencia se incrementa debido a la intensa acción antropogénica que caracteriza al área. Ésta incluye un indiscriminado cambio en el uso del suelo, tala inmoderada, quema de pastizales y sobrepastoreo (caprino

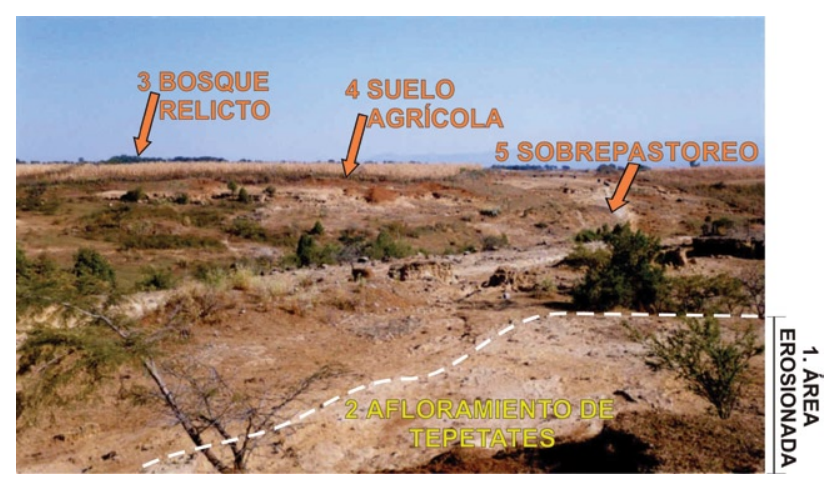

Figura 8. El Glacís de Buenavista como ejemplo de degradación del suelo y retrogresión del ecosistema. Esta fotografía ilustra la extensión que ocupan las áreas severamente erosionadas (1) en las que afloran los tepetates (2). La deforestación (3) el cambio de uso del suelo con fines agrícolas (4) y el sobrepastoreo (5) son los principales agentes que propiciaron este deterioro ambiental. 


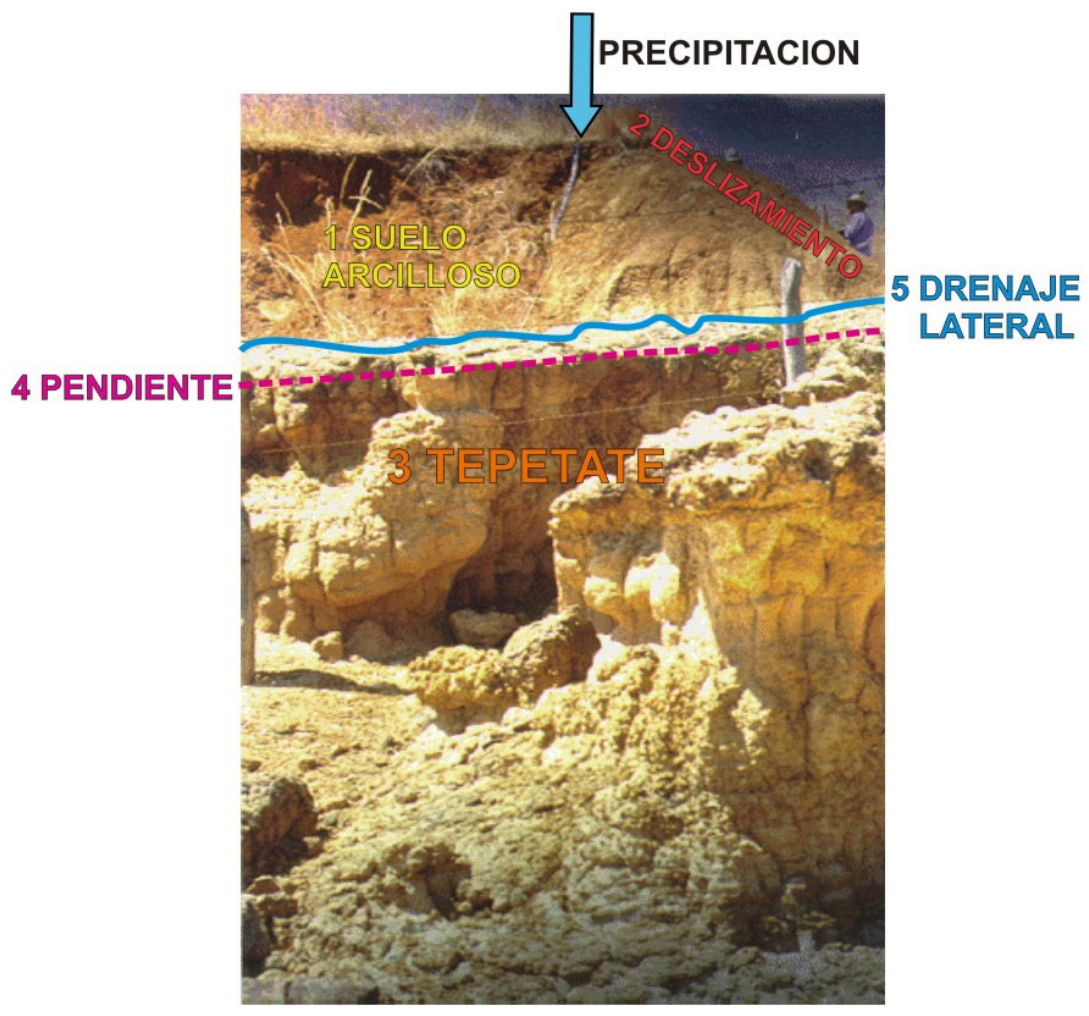

Figura 9. Hidroerosión, deslizamientos y drenaje lateral. Se observa la presencia de un suelo muy arcilloso (1) caracterizado por su índice alto de plasticidad y su bajo límite líquido, lo que propicia deslizamientos parciales de este material (2). Dicho suelo, sobreyace a un tepetate casi impermeable (3) condición, que junto con la pendiente (4) favorece una escorrentía alta y la formación de un drenaje lateral (5) el cual se desarrolla entre el suelo y el tepetate.

y vacuno). Todas estas prácticas, además de propiciar una baja cobertura vegetal de suelo, la cual en algunas de las áreas es nula, favorecen una erosión acelerada (Figuras 4, 5 y 8). Dichas áreas, denominadas "sitios críticos" (Bergsma et al., 1996) requieren de un control inmediato para evitar que la degradación se propague a otras áreas aledañas (Figura 8).

Por otra parte, el contenido pobre de materia orgánica que presentan estos suelos y los tepetates asociados a ellos (Tabla 2) propicia un decremento en la población y en la actividad metabólica de la fauna y flora del suelo.

En cuanto a la degradación física, la mejor evidencia se tiene por la escasa formación de agregados inestables, lo cuales le confieren al suelo y de modo especial a los tepetates, una estructura débil, poco porosa y con frecuencia compactada. Esto se traduce a su vez, en una limitada infiltración retención, transporte y distribución del agua y del aire, así como de compuestos orgánicos, químicos y minerales en el suelo.

Aunado a lo anterior, se estimó en forma cuantitativa, que los bajos porcentajes de materia orgánica, los altos contenidos de arenas y limo, la baja permeabilidad y la deficiente estructura que presentan los tepetates y suelos (Tablas 1 y 2) les confiere un riesgo alto de susceptibilidad a la erosión (Factor K) y al movimiento de masas (Flores Román et al., 1992 y 1996).
5.1. Los tepetates como un factor generador de erosión hídrica, contaminación y salinidad y/o sodicidad secundarias

La baja permeabilidad que caracteriza a los tepetates, el gradiente en que se localizan y la gran longitud de las pendientes que ocupan, aunado a una escasa cobertura vegetal y a una precipitación alta $(>800 \mathrm{~mm})$ resultan en un severo escurrimiento superficial y un intenso drenaje lateral cuando un suelo sobreyace al tepetate. En el primer caso, la escorrentía genera erosión, ya que disgrega, remueve y transporta, pendiente abajo, grandes volúmenes de suelo que en algunas áreas pueden estimarse, de acuerdo a la metodología propuesta por FAO-PNUMA (1980) en 50 t/ha/año. Dicho fenómeno comprende la erosión por salpicadura, la erosión laminar y la erosión en cárcavas así como diversos tipos de movimientos de masas, entre ellos: corrientes de lodo, solifluxión y deslizamientos. Estos últimos son frecuentes, de modo particular, cuando al tepetate le sobreyace un suelo de textura arcillosa con un bajo índice de límite líquido (Figura 9).

Normalmente, los materiales transportados son depositados en la base de la pendiente, propiciando la contaminación de los cuerpos de agua, construidos por los campesinos para su uso como abrevaderos, granjas piscícolas o fuentes para la irrigación. 

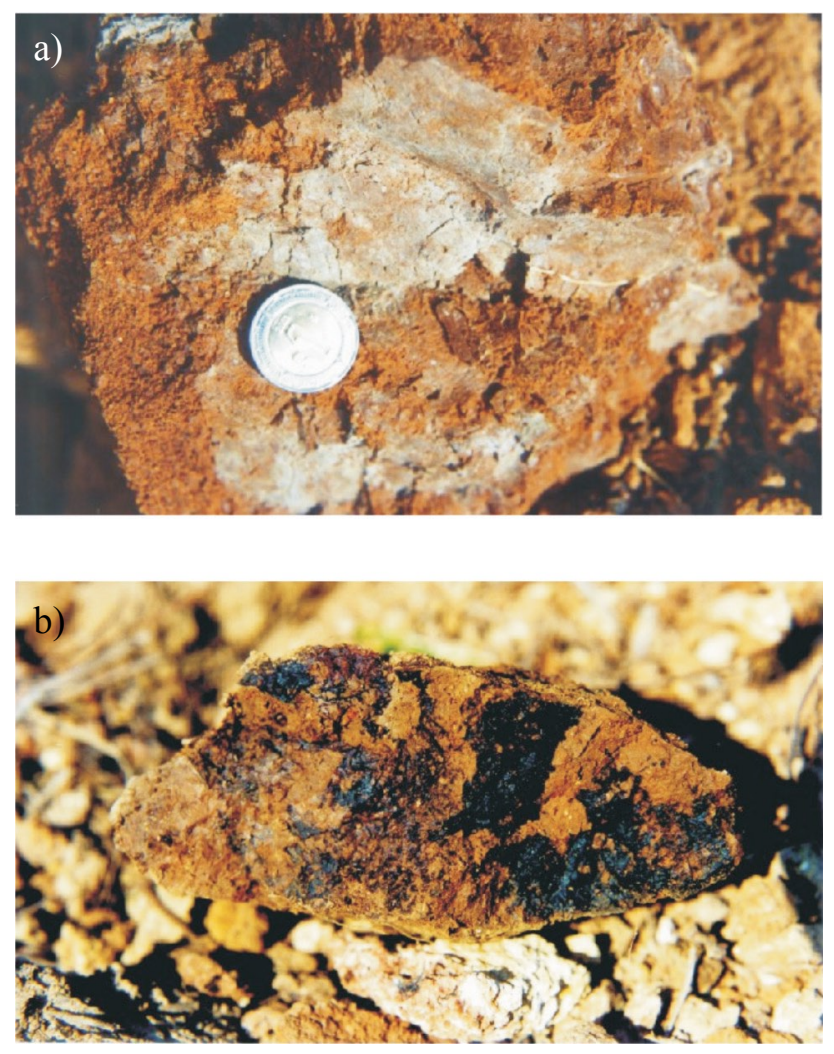

Figura 10. Rasgos hidromórficos que presentan los suelos del Glacis sobre los tepetates en el sitio de la Figura 9. a) Ped que muestra moteados de color gris por procesos de reducción y lavado de hierro. b) Ped con acumulaciones de óxidos de manganeso.

En el caso del drenaje lateral, éste se presenta debido a la abrupta diferencia de permeabilidad que existe en el contacto que limita al suelo del tepetate. En estas condiciones, especialmente si prevalece localmente un gradiente de pendiente $>3 \%$, el agua filtrada a través del suelo, se desliza sobre el tepetate a favor de la pendiente (drenaje lateral) (Figura 9).

En campo se observó que si la pendiente es plana $(<1 \%)$ o casi plana $(<3 \%)$ el agua se estanca, favoreciendo condiciones de anaerobiosis e hidromorfismo (redox) en el subsuelo, restrictivas para el crecimiento radicular de los cultivos. La micromorfología de estos materiales evidencia dichas condiciones. Los suelos que sobreyacen a los tepetates en estas condiciones, muestran fuertes rasgos de hidromorfismo, en forma de moteados grises (Figura 10a) $\mathrm{y}$ acumulaciones de manganeso (Figura 10b).

Además, se debe resaltar que la formación de un drenaje lateral, frecuentemente tiende a abatir la fertilidad natural del suelo, ya que contribuye al lavado y pérdida de sales solubles (desbasificación) de la materia orgánica contenida en él, así como de sus elementos texturales más finos, como es el caso de los limos y de las arcillas. Esta pérdida de bases se observa claramente en los suelos por sus bajas relaciones molares bases/alúmina, oscilando de 0.03-0.11 (Escamilla-Sarabia et al., 2002) y bajos valores de capacidad de intercambio catiónico de 11 a 22 mequ/100 $\mathrm{g}$ y de $\mathrm{pH}$ entre 5 y 6 (Solleiro-Rebolledo et al., 1999). Este proceso, colateralmente, también genera la destrucción de la estructura del suelo que está en contacto con el tepetate, sustituyéndolo gradualmente por una capa arenosa muy erodable y muy colapsable ante cargas confinadas (v.g. maquinaria agrícola). Cuando esta capa se colapsa, tiende a compactarse adquiriendo características análogas al tepetate que sobreyace.

Potencialmente, las sales que son transportadas por el drenaje natural pueden depositarse en la base de la pendiente, creando un riesgo de salinidad y sodicidad secundarias para los cultivos que ahí se localizan. Sin duda este riesgo se maximiza cuando además de las sales, el drenaje lateral también transporta agroquímicos y pesticidas provenientes de la parte alta del Glacis.

\section{Consideraciones generales sobre la habilitación de los tepetates en México}

Una vez que los tepetates afloran en un área, ésta no puede ser utilizada con fines agrícolas. Por lo tanto, es necesario modificar las características físicas y químicas del tepetate para mejorar su calidad productiva. Desde hace vario siglos, los tlaxcaltecas tenían conocimiento sobre la problemática que representan los tepetates, así como la forma para incorporarlos a la agricultura (Ruíz, 1987). Una de estas formas era por medio de la quema de las pencas de maguey y la adición de las cenizas al tepetate, con lo cual incorporaban nutrimentos; otra forma consistía en el cultivo de especies resistentes. Arias (1992) menciona que el laboreo y la fertilización de los tepetates existen desde tiempos prehispánicos. Esto se realizaba a través de relleno con suelo fértil o preparando el terreno mediante el rompimiento de la costra superior, la pulverización de terrones y la fertilización a través de la quema de hojas de maguey.

Como se ha mencionado, una de las principales limitantes de los tepetates es su estructura masiva y alta dureza, por lo que se considera que para iniciar con una habilitación para uso agrícola es necesario primero roturarlo por medio de herramientas comunes como pico, cincel y martillo o en algunos casos se ha hecho con maquinaria. Sin embargo, aún después de su roturación, es notable la ausencia de agregados, por lo que requieren de prácticas agrícolas adecuadas (Navarro y Flores, 1997; Prat et al., 2002).

En el caso del Glacis de Buenavista, no se han realizado medidas de rehabilitación, aunque en zonas aledañas, en donde se presentan tepetates de características similares, se han hecho experimentos detallados para volverlos productivos (Velásquez et al., 2001; García, 2005). En dichas investigaciones los autores han roturado el tepetate, usado enmiendas con estiércol de bovino, composta y vermicomposta, plantado higuera y pasto Rhodes, obteniéndose un buen grado de agregación y aumento en el contenido de materia orgánica. Sin embargo la adición de materia 
orgánica y prácticas de labranza mínima debes ser continua para evitar su endurecimiento posterior. Por lo tanto, estos procesos llegan a ser sumamente costosos, consecuentemente su uso es limitado.

\section{Conclusiones}

El estudio de los tepetates en México es un aspecto que coadyuva al entendimiento de la dinámica de la degradación del paisaje, ya que por sus propiedades (baja porosidad, fertilidad, retención de humedad, conductividad hidráulica) impiden el desarrollo radical y la infiltración de agua. Asimismo promueven el escurrimiento superficial y subsuperficial, que produce deslizamientos y erosión.

Estos horizontes endurecidos son comunes en el Eje Neovolcánico, presentándose principalmente en los piedemontes de las sierras volcánicas. En el Glacis de Buenavista, Morelos, subyacen a suelos arcillosos, en una superficie de baja inclinación $\left(5^{\circ}\right)$. Estos tepetates representan flujos hiperconcentrados formados a fines del Pleistoceno, que se encuentran sobre los depósitos de la Formación Cuernavaca, la cual constituye un abanico volcaniclástico con materiales procedentes del volcán Zempoala. Estas diferencias producen materiales con propiedades físicas y mecánicas muy contrastantes que contribuyen a intensificar la erosión hídrica y los movimientos de masas. Desde el punto de vista agrícola, los suelos arcillosos que sobreyacen a los tepetates poseen una baja fertilidad, por lo que los campesinos los abandonan, iniciándose una erosión intensa. En consecuencia, los tepetates afloran, de tal forma que el Glacis presenta un paisaje sumamente degradado, sin cobertura vegetal, sin suelos y con pocas posibilidades de rehabilitar el sistema, pues no hay recarga de agua en el acuífero ya que el escurrimiento es más fuerte que la infiltración mínima. Rehabilitar un sistema de este tipo es costoso y de largo tiempo.

\section{Agradecimientos}

Este trabajo se hizo con recursos de los proyectos PAPIIT IN112205. Se agradece los comentarios de M.C. Gutiérrez Castorena y de Gerd Werner, asimismo las sugerencias aportadas por Carolina Jasso Castañeda los cuales enriquecieron el trabajo.

\section{Referencias bibliográficas}

Arias, R.H., 1992, Rehabilitación de tepetates una alternativa para la producción agropecuaria y forestal: Terra 10, 309-317.

Bergsma, E.P., Charman, F., Gibbons, H., Hurni, W.C., Moldenhauer, and Panichapong, S., 1996, Terminology for soil erosion and conservation: Soil and Water Conservation of the International Society of Soil Science, 313.

Bertaux, J. and Quantin, P., 1994, Relation géométrique et variations minéralogiques des différents termes d'une sécuence d' altération de tufs pyroclastiques de la région de Texcoco (Mexique), en
Transactions of the $15^{\text {th }}$ International Congress of Soil Science: Acapulco, Mexico, 5, 232-233.

Cervantes, V., Gama-Castro, J., Hernández, G. and Meave, J., 2005, The land classification system of San Nicolás Zoyatlan (México) Nahuatl Indigenous community: Human Ecology Review, 12, 44-59.

Dubroeucq, D., Quantin, P. y Zebrowski, C., 1989, Los tepetates de origen volcánico en México. Esquema preliminar de clasificación: TERRA 7, 3-12.

Escamilla-Sarabia, G., Solleiro-Rebolledo, E., Sedov, S. y Gama-Castro, J., 2002, Tepetates del Glacís de Buenavista, Morelos: Interacción de procesos geomorfológicos y pedogenéticos: Investigaciones Geográficas, Boletín del Instituto de Geografía, UNAM, 48, 7689.

Etchevers, D.J., Rosa, M., López-Claude, Zebrowski y Peña, D, 1992, Características químicas de tepetates de referencia de los estados de México y Tlaxcala, México: TERRA 10, 171-182.

Food and Agriculture Organization of the United Nations, y Programa de las Naciones Unidas para el Medio Ambiente (FAO-PNUMA), 1980, Metodología provisional para la evaluación de la degradación de los suelos: Rome, 86 .

Food and Agriculture Organization of the United Nations, y United Nations Educational, Scientific and Cultural Organization (FAO-UNESCO), 1984, Proteger y Producir. Conservación del suelo para el desarrollo: Rome, 40 .

Food and Agriculture Organization of the United Nations (FAO), 1991, Guidelines: land evaluation for extensive grazing. Soils Bulletin 58: Rome.

Figueroa, S, B., 1975, Pérdida de suelo y nutrimentos y su relación con el uso del suelo en la cuenca del río Texcoco. Colegio de Posgraduados, Chapingo, México, Tesis de Maestría en Ciencias.

Flores-Román D., González-Velázquez, A., Alcalá-Martínez, J. R. y GamaCastro, J.E., 1990, Los Tepetates: Revista del Instituto Nacional de Estadística, Geografía e Informática, 3, No. 4.

Flores-Román, D., Alcalá-Martínez, J, R., González-Veláquez, A. y. Gama-Castro, J, E., 1992, Suelos con fragipán de origen volcánico en clima semicálido y subhúmedo, El caso del Noreste del estado de Morelos: 151-163.

Flores-Román, D., Alcalá Martínez, J., R., González-Veláquez, A. and Gama-Castro, J, E., 1996, Duripans in the subtropical and temperate subhumid climate of the Trans-Mexico Volcanic Belt: Revista Mexicana de Ciencias Geológicas, 13 (2), 228-239.

Gama-Castro, J,E., MCClung, E., Solleiro-Rebolledo, E., Ibarra, E., Sedov, S., Jasso, C., Vallejo, E., Puig, T. and Cabadas, H., 2005, Incorporation of Ethnopedological knowledge in the study of soils in the Teotihuacan valley, Mexico: Journal of Eurasian Soil Science, 38, 95-98.

Gama-Castro, J,E., Solleiro-Rebolledo, E., Sergey, S. y Cabadas-Baez, H., 2006, El Recurso Suelo: en Patrones de utilización, deterioro y restauración de los recursos naturales de México. Edit. Facultad de Ciencias, UNAM. (en prensa).

García, E.A., 1961, Estudio de los suelos tepetatosos y las posibilidades de recuperación agrícola: Chapingo, México, Escuela Nacional de Agricultura, Tesis Licenciatura.

García, A., 2005, Habilitación de un tepetate por efecto de mejoradotes biológicos: Tesis de maestría. Posgrado en Ciencias Biológicas, Instituto de Geología, UNAM. $101 \mathrm{pp}$.

Geissert, A., 1992, Los tepetates de Xalapa, Veracruz México: relación con el relieve modelado actual y esquema cronológico: TERRA $10,221-225$.

Geissert, D. y Dubroeucq D., 1990, Los tepetates del área de Xalapa, Veracruz y su relación con la paleosuperficie. Una perspectiva cronológica: TERRA 8, 148-155.

Gibson, Ch. 1996. Los Aztecas bajo el dominio español, 1519-1810: Editorial Siglo XXI, S.A. de C.V., $13^{\mathrm{a}}$ edición, México, D.F.

Guerrero, E., Luna-Mosqueda J.L. y Caballero-Ochoa E., 1992, Distribución de los tepetates de la República Mexicana escala 1:4,000,000: TERRA 10, 131-136.

Gutierrez-Castorena, y Ortiz-Solorio, C.A., 1992, Caracterización del tepetate blanco en Texcoco, México: TERRA, 10, 202-209.

Heine, K. and Schönhals, E. 1973. Entstehung und Alter der "toba"- 
Sedimente in Mexiko. Eiszeitalter und Gegenwart 23/24, 201 215.

Hidalgo, C., Quantin P., Zebrowski, C., 1992, La cementación de tepetates: estudio de la silicificación: TERRA 10, 192-201.

Instituto Nacional de Estadística, Geografía e Informática, (INEGI), 2003, Información Nacional sobre Perfiles de Suelo, Versión 1.2., México, 25.

Llerena, L.D., 1947, El distrito de conservación del suelo y agua de Chapingo, México: Chapingo, México, Escuela Nacional de Agricultura, tesis de licenciatura.

Martínez, G. y López, J., 2005, Caracterización de las unidades ambientales biofísicas del Glacís de Buenavista, Morelos, mediante la aplicación del enfoque geomorfológico morfogenético: Investigaciones Geográficas, Boletín del Instituto de Geografía, UNAM, 48, 3453.

Miehlich, G., 1992, Formation and properties of tepetate in the central highlands of Mexico: TERRA 10, 137-144.

Navarro G., H y Flores, D.S., 1997, Manejo agronómico diferencial de la asociación maíz-haba en tepetate de quinto año de uso agrícola. In: Tercer Simposio Internacional: Suelos Volcánicos y Endurecidos, en Zebrowski, C., Quantin, Py Trujillo, G. (eds.), ORSTOM. Quito, Ecuador. 287-295.

Nimlos, T.J., 1990, Morphology, genesis and classification of soils formed over Mexican Tepetate: Soil Survey Horizonts, 30 (3) 72-77.

Nimlos, T.J. and Ortiz-Solorio, C.A., 1987, Tepetate the rock mat: Soil Water Conservation, 42, 83-86.

Nimlos, T.J. and Hillery, P.A. 1990. The strength/moisture relations and hydraulic conductivity of Mexican tepetate. Soil Science, 150:425430.

Oldeman, L.R., 1988, Guidelines for general assessment of the status of human-induced soil degradation. Working paper 88/4: International Soil Reference and Information Centre (ISRIC), Wageninen, $151 \mathrm{p}$.

Oropeza, J.L., Ríos, B. y Salazar J.D., 1997, Uso de modelos matemáticos de erosión hídrica para la optimización de la rehabilitación de tepetates con fines agrícolas, en Zebrowski, C., Quantin, P., Trujillo, G. (Eds.), Suelos volcánicos endurecidos. III Simposio Internacional. Quito, Ecuador, 384-396.

Ortiz, P.M., 1977, Estudio geomorfológico del Glacis de Buenavista, estado de Morelos., Boletín del Instituto de Geografía, UNAM, México, 8, 25-40.

Ortiz-Solorio, C.A., 1986, Evaluación de la velocidad de desertificación en la cuenca del rio Texcoco (efecto de la tecnología aplicada, inversiones y factor humano: México: Colegio de Postgraduados, Montecillo, México, tesis de Maestría en Ciencias.

Ortiz-Solorio, C.A. 1999. Los levantamientos etnoedafológicos: Colegio de Postgraduados, Montecillo, México, Tesis de Doctor en Ciencias.

Pacheco, L.M.C., 1979, Cartografía y caracterización mineralógica de los tepetates del oriente del Valle de México: México, Universidad Autónoma de Chapingo, Tesis Licenciatura.

Palacio-Prieto, J.L., 1982, Análisis geomorfológico de la región de Cuernavaca-Tenancingo-Ixtapan de la Sal, estados de Morelos y México: México, Facultad de Filosofía y Letras, División de estudios de Posgrado, UNAM, Tesis de Maestría,

Peña H.D., Miranda, M.E., Zebrowski, C. y Arias, M. H., 1992, Resistencia de los tepetates de la vertiente occidental de la Sierra Nevada: TERRA, 10, 164-177.

Peña, H.D., y Zebrowski, C., 1992, Los suelos y tepetates de la vertiente occidental de la Sierra Nevada: TERRA, 10, 151-163.

Poetsch, T., 2004. Forms and dynamics of silica gel in a tuff-dominated soil complex: Results of micromorphological studies in the Central Highlands of Mexico: Revista Mexicana de Ciencias Geológicas 21 (1), 195-201.

Prat, C., Baez, A. y Márquez, A., 1997, Erosión y escurrimiento en parcelas de tepetate en Texcoco, México, en Zebrowski C., Quantin, P., Trujillo, G. (Eds.), Suelos volcánicos endurecidos. III Simposio Internacional. Quito, Ecuador, 378-384.

Prat C., Ordaz V., Rugada J.A., 2002, Impacto de la roturación y del manejo agronómico de un tepetate sobre su estructura: TERRA 21, 109-115.
Quantin, P., 1992, L' induration des materiaux volcaniques pyroclastiques en America Latine: processus geologiques et pedologiques: TERRA, 10: 24-33.

Quantin, P., Arias, A., Etchevers, J.D., Ferrera, R., Oleshko, K., Navarro, H., Werner G. y Zebrowski C., 1993, Tepetates de México: caracterización y habilitación para la agricultura (Informe científico final del Proyecto TS2-A 212-C CEE/ORSTOM): TERRA 10, 178-182.

Rey, C.J.A., 1979, Estimación de la erodabilidad de los tepetates en la cuenca del río Texcoco en base al factor K: Chapingo México, Colegio de Postgraduados, tesis de Maestría en Ciencias.

Rodríguez, S., Gutiérrez-Castorena, M.C., Hidalgo, C. y. Ortiz-Solorio, C.A., 1999, Intemperismo en Tepetates y en cenizas volcánicas y su influencia en la formación de Andisoles: TERRA, 17, 97-108.

Ruíz, F.J,. 1987, Uso y manejo de los tepetates para el desarrollo rural: Universidad Autónoma Chapingo. Chapingo, México, 222 pp.

Salazar, L., 1938, Elementos de Geología: Universidad Nacional Autónoma de México pp. 192-33.

Servenay, A., Prat, C., Sorani V. y González, E., 1996, Estudio espacial de los tepetates del eje neovolcánico mexicano: metodología para un programa de investigación. en Zebrowski, C., Quantin, P., Trujillo, G. (Eds.), Suelos volcánicos endurecidos. III Simposio Internacional. Quito, Ecuador, 149-153.

Shaw, F.Ch. 1929. Extracto de las Conferencias sobre Formación, Clasificación y Utilización de los SuelosIn: Boletín del Colegio Agrológico de Meoqui, Chihuahua. México. pp. 24-36.

Solleiro-Rebolledo E., Gama-Castro J.E., Palacios-Mayorga S., Sedov, S., Shoba S.A., 1999. Late Pleistocene paleosols in Central Mexico: genesis and paleogeographic interpretation: Eurasian Soil Science 32: 1077-1083.

Solleiro-Rebolledo E., Sedov, S., Gama-Castro, J.E., Flores-Román, D. and Escamilla-Sarabia, G., 2003, Paleosol-Sedimentary sequences of the Glacis de Buenavista, Central Mexico: Interaction of late Quaternary pedogenesis and volcanic sedimentation: Quaternary International 106-107: 184-201.

SSS-USDA, 1998, Keys to Soil Taxonomy. Eighth edition USDA. Soil Conservation Service. U.S. Government Printing Office. Washington, D.C.

Trueba, C.A., 1979, Reincorporación de terrenos degradados a la producción: Secretaría de Agricultura y Recursos Hidráulicos. Dirección General de Conservación del Suelo y del Agua. México, D.F.

Valdés, L.A., 1970, Características morfológicas y mineralógicas de los suelos de tepetate de la Cuenca de México: México, tesis de Maestría en Ciencias.

Velásquez, A., Flores, R.D. y Acevedo, O., 2001, Formación de agregados en tepetate por influencia de especies vegetales. Agrociencia 35, $311-320$.

Williams, B.J., 1980, Pictorial representation of soils in the Valley of Mexico: evidence from the codex Vergara: Geosciences and Man, 21, 51-61.

Williams, B.J. y Ortiz-Solorio, C., 1981, Middle American folk soil taxonomy: Annals of the Association of American Geographers, $71,335-358$

Zebrowski, C., 1992, Los suelos volcánicos endurecidos en América Latina, en TERRA, 10, 15-23.

Manuscrito recibido: Abril 30, 2007

Manuscrito corregido recibido: Junio 20, 2007

Manuscrito aceptado: Julio 3, 2007 